\title{
Multiple Antibiotic Resistant Index of Gram-Negative Bacteria from Bird Droppings in Two Commercial Poultries in Enugu, Nigeria
}

\author{
Ruth Asikiya Afunwa ${ }^{*}$, Johnpaul Ezeanyinka ${ }^{2}$, Emmanuel Chijindu Afunwa ${ }^{3}$, \\ Adaeze Suzzy Udeh², Nnamdi Angus $\mathrm{Oli}^{4}$, Marian Unachukwu ${ }^{2}$
}

\footnotetext{
${ }^{1}$ Department of Pharmaceutical Microbiology and Biotechnology, Faculty of Pharmaceutical Sciences, Chukwuemeka Odumegwu Ojukwu University, Igbariam, Anambra State, Nigeria

${ }^{2}$ Department of Biological Sciences, Faculty of Natural and Applied Sciences, Godfrey Okoye University, Enugu State, Nigeria ${ }^{3}$ Department of Clinical Pharmacy, Faculty of Pharmaceutical Sciences, University of Nigeria, Nsukka, Enugu State, Nigeria ${ }^{4}$ Department of Pharmaceutical Microbiology, Faculty of Pharmaceutical Sciences, Nnamdi Azikiwe University, Agulu, Anambra State, Nigeria

Email: *missruthus2000@yahoo.com
}

How to cite this paper: Afunwa, R.A. Ezeanyinka, J., Afunwa, E.C., Udeh, A.S., Oli, N.A. and Unachukwu, M. (2020) Multiple Antibiotic Resistant Index of Gram-Negative Bacteria from Bird Droppings in Two Commercial Poultries in Enugu, Nigeria. Open Journal of Medical Microbiology, 10, 171-181.

https://doi.org/10.4236/ojmm.2020.104015

Received: August 17, 2020

Accepted: November 2, 2020

Published: November 5, 2020

Copyright $\odot 2020$ by author(s) and Scientific Research Publishing Inc. This work is licensed under the Creative Commons Attribution International License (CC BY 4.0).

http://creativecommons.org/licenses/by/4.0/

\section{(c) (i) Open Access}

\begin{abstract}
Antimicrobial resistance refers to the ability of microorganisms to grow in the presence of an antimicrobial agent at a concentration that will normally kill or inhibit their growth. Antimicrobial resistance has become a major global threat making treatment of infections tougher especially with high cost of treatment in humans and animals. This study was done to determine the Multiple Antibiotic Resistant Index (MARI) of Gram-negative bacteria from bird droppings in two commercial poultries in Enugu. Forty (40) samples were collected from each of the poultries. Isolates were identified by standard microbiological methods. The isolates identified were Escherichia coli, Klebsiella pneumoniae, Pseudomonas aeruginosa, Citrobacter spp, Proteus spp. and, Enterobacter spp. Antibiotic susceptibility testing was carried out using disc diffusion technique. The organisms were tested against pefloxacin, augmentin (amoxicillin and clavulanic acid), ceftazidime, streptomycin, ciprofloxacin, gentamycin, cephalothin, neomycin and ofloxacin. The result of the susceptibility test showed that Proteus spp had the highest resistance and MARI value of 0.5 and 1.0 respectively. The other MARI values were Escherichia coli (0.9), Klebsiella pneumonia (0.9), Pseudomonas aeruginosa (0.8), Citrobacter spp (0.8) and Enterobacter spp (0.7). These results suggest that bacterial organisms from poultry source can contribute significantly to the spread of multi-antibiotic resistant organisms. This could arise from the indiscriminate use of antibiotics in bird feeds in poultries.
\end{abstract}




\section{Keywords}

Antibiotic, Poultry, Gram Negative Bacteria, Multi-Drug Resistance, Antibiotic Susceptibility

\section{Introduction}

Antimicrobial Resistance (AMR) has become a big threat to global health. It has risen to dangerously high levels in all parts of the world, making it difficult to treat infectious diseases [1]. This has led to the use of expensive second or third-generation antibiotics and prolonged hospital stay which then translates to higher hospital bills [2]. The high rates of antimicrobial resistance occurrence have attracted the attention of international bodies such as the World Health Organization (WHO), Food and Agriculture Organization (FAO) and, the World Organization for Animal Health who have now forged a united approach to combat it as a common force [1]. It is estimated that worldwide, 700,000 patients die annually as a result of resistant infections and if nothing is done to combat antimicrobial resistance, the death rate is estimated to escalate to $10 \mathrm{mil}-$ lion by the year 2050 [3].

Antimicrobials are also used in animals to treat animal diseases and as growth promoters to increase productivity [4]. These animals are important to the well-being of humans as they contribute to human nutrition and wealth especially in countries where the livestock are a major source of income. Any increase in the prevalence of antimicrobial resistance organisms will impact negatively directly and indirectly. To avoid economic loses, livestock farmers are tempted to use more effective and often more expensive antimicrobial in treating sick animals, thus ending-up infringing upon those that are last line options for use in humans; especially if they can easily be bought over the counter [2]. This ends-up in the development of resistance to the few antimicrobials that are relied upon for treating human infections. The microorganisms that are mainly involved in the infection process both in hospital and community are called ESKAPE pathogens (Enterococcus faecium, Staphylococcus aureus, Klebsiella pneumoniae, Acinetobacter baumannii, Pseudomonas aeruginosa and, Enterobacteriaceae) emphasizing their capacity to "escape" from common antibacterial treatments [5] [6].

The poultry industry is one of the largest and fastest-growing agro structures in Africa and the world. This can be attributed to increasing demand for poultry meat and egg products. These high demands of poultry products have also led to the large-scale accumulation of wastes including manure and litter which may pose disposal and pollution problems to man and the environment. Resistance bacteria of animal origin can be transmitted from animals to humans through the food supply, water or, through direct contact with animals. Sometimes resistant genes can be transferred from animals through human pathogens that are 
normally human-specific. Contaminated food of animal origin is one source of human bacterial infections when consumed; therefore, the presence of antibiotic-resistant strains in the animal foods such as poultry has raised concerns that the treatment of human infections will be compromised [7] [8]. It has resulted in disease burden, high cost of treatment and, a continuous spread of resistant microbial pathogens [3] [9]. Multiple Antibiotic Resistance (MAR) index is a valid and useful method of tracking especially bacterial infections and drug resistance. MAR index is calculated as the ratio of the number of antibiotics to which an organism is resistant to the total number of antibiotics to which the organism is exposed. Bacteria having MAR index $\geq 0.2$ originate from a high-risk source of contamination where several antibiotics are used [10] [11] [12]. Thus, it became imperative to investigate the significance of multi-antibiotic resistant bacteria of poultry source in the emergence and, spread of antibiotic resistance in Enugu metropolis, Nigeria and also evaluate the MAR indices of the isolates.

The limitation of this study was the inability of the authors to collect adequate representative samples for the study. This was due in part to frequent collection of the droppings as manure for their farms by the natives.

\section{Materials and Methods}

\subsection{Study Area and Samples Collection}

The study was carried out in Enugu State, Nigeria. Fecal droppings were obtained from two commercial poultry farms in Emene and Abakpa. A total of forty (40) samples of fresh bird droppings were collected from each of the two commercial poultry farms located in Enugu metropolis over a period of 4 weeks (September 20 - October 18, 2019). A 1 g poultry dropping sample was collected in sterilized Mac Cartney bottle that contained peptone water and was transported to the research laboratory for bacteriological analysis within an hour of collection. The two poultry farms are located in a densely populated area with frequent farming practices. The farmers use the bird droppings as manure for their crops to boost yield.

The sample size was based on the availability of fresh droppings on sample collection days within the sample collection duration of four weeks. Samples were randomly collected from poultry sites.

\subsection{Isolation of Bacteria from Poultry Droppings}

Bacteriological examinations were carried out using standard methods for aerobics bacteria [13]. Samples collected in Mac Cartney bottles were gently shaken and stirred with a sterile glass rod until mixed thoroughly, $1.0 \mathrm{ml}$ was transferred into the test tube containing $9.0 \mathrm{ml}$ of distilled water and serial dilution was carried out. Aliquots of each suspension were evenly spread plating on nutrient agar, Mac Conkey agar. (They were grown on Mac Conkey as a selective and differential medium due to the preference for Gram-negative organisms in this study). The plates were incubated for 24 hours at $37^{\circ} \mathrm{C}$ aerobically and growth of 
the colony was characterized and representative colonies were selected and purified by successive sub-culturing. The identification of bacteria was done based on their morphology, Gram staining, and biochemical tests. Different biochemical tests used for Gram-negative include indole, urea, Simon's citrate agar, lysine iron agar, oxidase, sugar fermentation and motility [14].

\subsection{Antibiotics Disc}

Antibiotic discs used include Pefloxacin $(30 \mu \mathrm{g})$, Ciprofloxacin $(30 \mu \mathrm{g})$, Ceftazidime $(30 \mu \mathrm{g})$, Augmentin (Amoxicillin and clavulanic acid combination) (30 $\mu \mathrm{g})$, Gentamicin $(30 \mu \mathrm{g})$, Streptomycin $(30 \mu \mathrm{g})$, Cephalotin $(30 \mu \mathrm{g})$, Ofloxacin $(30 \mu \mathrm{g})$, Neomycin $(30 \mu \mathrm{g})$.

\subsection{Determination of Susceptibility of Bacteria Isolates}

\subsubsection{Disc Diffusion Method}

A $20 \mathrm{ml}$ volume of Mueller Hinton agar was prepared and dispensed aseptically into $90 \mathrm{~mm}$ Petri dishes. A loopful of each isolate was inoculated into $100 \mathrm{ml}$ of nutrient broth and cultured overnight. From a $100 \mu \mathrm{l}$ of each of the isolates equivalent to $0.5 \mathrm{ml}$, MacFarland standard was aseptically seeded into the Mueller Hinton agar plate. This was allowed to dry. The antibiotic disc was aseptically placed on the surface of the Muller Hinton agar and allowed for 30 minutes to pre-diffuse. The set up was done in triplicate with a control containing no antibiotic disc. It was incubated for 24 hours at $37^{\circ} \mathrm{C}$ and thereafter, the inhibition zone diameters were measured. Values obtained were interpreted according to the Clinical and Laboratory Standards Institute [15].

\subsubsection{MARI Index}

MAR index is calculated as the ratio of the number of antibiotics to which an organism is resistant to the total number of antibiotics to which the organism is exposed. MARI is calculated as $a / b$, where $a=$ number of antibiotics isolate was resistant to $b=$ the total number of antibiotic used Bacteria having MAR index $\geq$ 0.2 originate from a high-risk source of contamination where several antibiotics are used [11] [12].

\section{Results}

\subsection{Phenotypic Identification of Isolates}

A total of twenty (20) isolates were obtained from the bird droppings collected from the two poultries. The six Gram-negative bacteria were isolated from the sample using morphological, biochemical characteristics and include Escherichia coli, Proteus spp, Klebsiella pneumoniae, Enterobacter spp, Citrobacter spp and Pseudomonas aeruginosa (Table 1).

The frequency of each of the isolates as show on Table 2 explains the distribution of the different isolates from the poultries. Escherichia coli was (7), Proteus spp (4), Klebsiella pneumonia (4), Enterobacter spp (2), Citrobacter spp (2) and Pseudomonas aeruginosa (1). The above distribution shows that $E$. coli had the 
Table 1. Phenotypic identification of isolates.

\begin{tabular}{|c|c|c|c|c|c|c|c|}
\hline Isolates & Citrate & Indole & Urease & Oxidase & Motility & $\begin{array}{c}\text { Lysine } \\
\text { iron agar }\end{array}$ & $\begin{array}{l}\text { Probable } \\
\text { organism }\end{array}$ \\
\hline 1 & - & + & - & - & Motile & - & Escherichia coli \\
\hline 2 & + & + & + & - & Motile & - & Proteus spp \\
\hline 3 & - & + & - & - & Motile & - & Escherichia coli \\
\hline 4 & + & + & + & - & Motile & - & Proteus spp \\
\hline 5 & - & + & - & - & Motile & - & Escherichia coli \\
\hline 6 & + & - & + & - & Non Motile & - & Klebsiella spp \\
\hline 7 & - & + & - & - & Motile & - & Escherichia coli \\
\hline 8 & + & + & + & - & Motile & - & Proteus spp \\
\hline 9 & - & + & - & - & Motile & - & Escherichia coli \\
\hline 10 & + & - & - & - & Motile & - & Enterobacter spp \\
\hline 11 & + & - & + & - & Non Motile & - & Klebsiella spp \\
\hline 12 & - & + & - & - & Motile & - & Escherichia coli \\
\hline 13 & + & + & + & - & Motile & - & Proteus spp \\
\hline 14 & + & - & + & - & Non Motile & - & Klebsiella spp \\
\hline 15 & + & - & - & - & Motile & - & Enterobacter spp \\
\hline 16 & - & + & - & - & Motile & - & Escherichia coli \\
\hline 17 & & - & & - & Motile & - & Citrobacter spp \\
\hline 18 & + & - & + & - & Non Motile & - & Klebsiella spp \\
\hline 19 & & - & & - & Motile & - & Citrobacter spp \\
\hline 20 & & - & & - & & - & $P$. aeruginosa \\
\hline
\end{tabular}

KEY: $(-)$ NEGATIVE, $(+)=$ POSITIVE.

Table 2. Frequency of isolation identified from both poultry farms.

\begin{tabular}{ccc}
\hline ISOLATES & POULTRY 1 & POULTRY 2 \\
\hline E. coli & 5 & 2 \\
Proteus spp & 3 & 1 \\
Klebsiella spp & 1 & 3 \\
Enterobacter spp & 1 & 1 \\
Citrobacter spp & 0 & 2 \\
Pseudomonas aeruginosa & 0 & 1 \\
TOTAL & 10 & 10 \\
\hline
\end{tabular}

highest frequency which also tallies to the findings of Chika et al., [16] who recoreded a total of $29 \mathrm{E}$. coli isolates from the 40 sample swabs collected.

The sensitivity results on Table 3 show that most of the isolates were resistant to the conventional antibiotics used. Proteus spp had the highest resistance to all the antibiotics tested while Escherichia coli and Citrobacter spp showed 
Table 3. Susceptibility pattern (Inhibition zone diameter in millimeters ( $\mathrm{mm}$ ) of the Isolates).

\begin{tabular}{|c|c|c|c|c|c|c|c|c|c|c|}
\hline Isolate & $\mathrm{CT}$ & OFX & $\mathrm{N}$ & PEF & GN & $\mathrm{AU}$ & CIP & ST & $\mathrm{CF}$ & $\mathrm{AM}$ \\
\hline E. coli & 0 & 0 & 5 & 6 & 14 & 15 & 6 & 3 & 2 & 0 \\
\hline Proteus spp & 5 & 4 & 0 & 0 & 0 & 0 & 0 & 0 & 0 & 0 \\
\hline E. coli & 2 & 6 & 12 & 14 & 40 & 20 & 6 & 8 & 1 & 1 \\
\hline Proteus spp & 20 & 15 & 0 & 16 & 12 & 11 & 30 & 15 & 0 & 2 \\
\hline E. coli & 0 & 12 & 4 & 30 & 0 & 23 & 15 & 0 & 15 & 0 \\
\hline Klebsiella pneumoniae & 0 & 0 & 6 & 40 & 0 & 0 & 15 & 4 & 6 & 8 \\
\hline E. coli & 0 & 0 & 7 & 15 & 0 & 23 & 14 & 0 & 0 & 2 \\
\hline Proteus spp & 15 & 0 & 6 & 5 & 0 & 11 & 32 & 0 & 5 & 11 \\
\hline E. coli & 3 & 0 & 1 & 4 & 14 & 0 & 2 & 4 & 12 & 8 \\
\hline Enterobacter & 30 & 0 & 0 & 23 & 6 & 8 & 17 & 22 & 6 & 0 \\
\hline Klebsiella pneumoniae & 0 & 0 & 3 & 6 & 5 & 0 & 34 & 0 & 8 & 8 \\
\hline E. coli & 0 & 15 & 4 & 23 & 8 & 9 & 0 & 8 & 0 & 40 \\
\hline Proteus spp & 0 & 0 & 6 & 4 & 7 & 32 & 5 & 4 & 0 & 3 \\
\hline Klebsiella pneumoniae & 7 & 0 & 8 & 0 & 0 & 23 & 7 & 23 & 0 & 8 \\
\hline Enterobacter spp & 0 & 4 & 25 & 1 & 5 & 9 & 12 & 15 & 0 & 17 \\
\hline E. coli & 0 & 7 & 18 & 7 & 3 & 4 & 4 & 30 & 4 & 1 \\
\hline Citrobacter spp & 15 & 8 & 0 & 8 & 8 & 7 & 7 & 19 & 6 & 0 \\
\hline Klebsiella pneumoniae & 0 & 5 & 2 & 4 & 0 & 17 & 6 & 1 & 7 & 15 \\
\hline Citrobacter spp & 0 & 30 & 7 & 0 & 4 & 19 & 6 & 0 & 30 & 7 \\
\hline Pseudomonas spp & 0 & 5 & 0 & 15 & 1 & 4 & 2 & 0 & 20 & 8 \\
\hline
\end{tabular}

$\mathrm{PEF}=$ Pefloxacin, $\mathrm{AU}=$ Augumentin (Amoxicillin/clavulanic acid), $\mathrm{AM}=$ Amoxicillin, $\mathrm{CT}=$ Ceftazidime, $\mathrm{ST}=$ Streptomycin, $\mathrm{CIP}=$ Ciprofloxacin, $\mathrm{GN}=$ Gentamycin, $\mathrm{CF}=$ Cephalotin, $\mathrm{N}=$ Neomycin, $\mathrm{OFX}=$ Of loxacin.

intermediary response to the antibiotics. The high resistant pattern of the isolates suggests that most of the isolates have lost sensitivity to the conventional antibiotics used in this study. Similar studies [16] in the Eastern parts of the country identified high resistant pattern to the antibiotics used with Escherichia coli showing the highest resistance.

This measures the resistance index of the isolates. MAR index is calculated as the ratio of the number of antibiotics to which an organism is resistant to total the number of antibiotics to which the organism is exposed. Bacteria having MAR index $\geq 0.2$ originate from a high-risk source of contamination where several antibiotics are used. Where 1) is the aggregate antibiotic resistance score of all isolates from the sample, 2) is the total number of antibiotics used. Proteus spp had the highest MARI index of 1.0 which confirms high resistance. This is in line with a study by [17], who identified the Enterobacteriaceae as the prevailing organisms identified from samples collected in poultry dropping. 


\subsection{Mean Distribution of MAR Index of Isolates between Poultries}

The ratio of the MARI distribution shows that there is an insignificant difference in the MAR index from the two poultries. High resistance is observed though the poultries are not situated in the same area. Figure 1 shows the mean distribution of the MARI index in the two poultry. Poultry 1 had a MARI index value of 0.73 while poultry 2 had $s$ value of 0.8 .

\section{Discussion}

The bacteria pathogen isolated were mostly Gram-negative bacteria with $E$. coli having the highest prevalence. The result is consistent with earlier reports [18] [19]. Although the isolates are part of the enteric flora of the poultry birds, they are of public health importance since they are implicated in antibiotic resistance. Another interesting aspect of this study is the use of the droppings as manure to boost local crops, there is a high possibility of antibiotic resistance gene transfer when the crops are consumed by humans and further transfer between individuals within the community [20]. The variations observed in the carriage of organisms in both poultries may be due to the environmental settings in which the birds are raised, nutrition and, the physiological state of the gut of animals which influence the distribution of organisms found [21].

The Multiple Antibiotic Resistance Index (MARI) as shown on Table 4 is an important analysis to check antibiotic resistance and health risk factors. MAR index is calculated as the ratio of the number of antibiotics to which an organism is resistant to total the number of antibiotics to which the organism is exposed. Bacteria having MAR index $\geq 0.2$ originate from a high-risk source of contamination where several antibiotics are used.

Organisms which have MAR indices of greater than $\geq 0.2$ confirm the presence of multidrug-resistant genes originating from the environment where there is an abuse of these drugs and also that the plasmids contain one or more resistance genes, each encoding a single antibiotic resistance phenotype [12] [22]. Using the MARI analysis is also simple and does not require specialized training and expensive equipment [11] [12], while also providing the needed data. Proteus spp is a common cause of community-acquired infection, its prevalence in this study suggests a chance infection spread if its proliferation is not controlled.

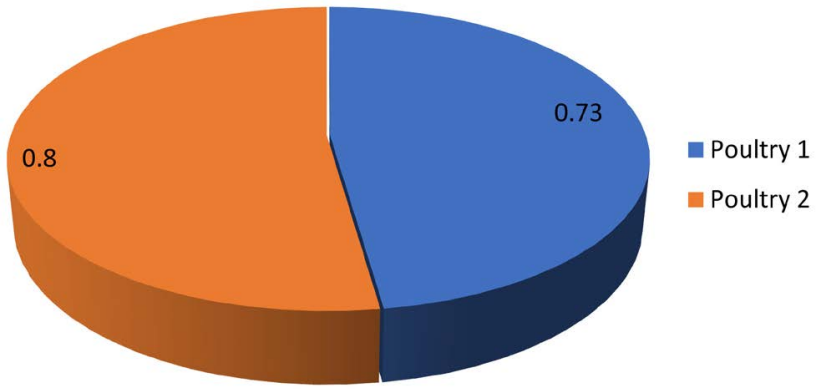

Figure 1. Mean distribution of mar index of isolates between poultry 1 and poultry 2 . 
Table 4. Multiple antibiotic resistance indices (MARI) of isolates.

\begin{tabular}{|c|c|c|}
\hline$S / N$ & Isolates & MAR Index \\
\hline 1 & Escherichia coli & 0.8 \\
\hline 2 & Proteus spp & 1.0 \\
\hline 3 & Escherichia coli & 0.7 \\
\hline 4 & Proteus spp & 0.5 \\
\hline 5 & Escherichia coli & 0.6 \\
\hline 6 & Klebsiella pneumoniae & 0.8 \\
\hline 7 & Escherichia coli & 0.7 \\
\hline 8 & Proteus spp & 0.8 \\
\hline 9 & Escherichia coli & 0.8 \\
\hline 10 & Enterobacter spp & 0.6 \\
\hline 11 & Klebsiella pneumoniae & 0.9 \\
\hline 12 & Escherichia coli & 0.7 \\
\hline 13 & Proteus spp & 0.9 \\
\hline 14 & Klebsiella pneumoniae & 0.8 \\
\hline 15 & Enterobacter spp & 0.7 \\
\hline 16 & Escherichia coli & 0.9 \\
\hline 17 & Citrobacter spp & 0.8 \\
\hline 18 & Klebsiella pneumoniae & 0.8 \\
\hline 19 & Citrobacter spp & 0.7 \\
\hline 20 & Pseudomonas spp & 0.8 \\
\hline
\end{tabular}

MAR index is calculated as the ratio of number of antibiotics to which organism is resistant to total number of antibiotics to which the organism is exposed. Where 1) is the aggregate antibiotic resistance score of all isolates from the sample, 2) is the total number of antibiotics used.

Pseudomonas and Klebsiella pneumoniae are also major pathogens in healthcare-associated infections. They are associated with significant morbidity in humans and are also difficult to manage with first-line antibiotics [23] [24]. The susceptibility test on Table 3, suggests high resistance to the Co-amoxiclav, Ceftazidime, Neomycin and, Amoxicillin. This observation is consistent with previous reports of [15] and [25] whose findings identified multidrug-resistant bacteria in poultry droppings. These organisms have very important implications on human health as antibiotic- resistant infections are difficult to treat and often require expensive antibiotics, long term therapy, and in extreme cases may lead to mortality. Resistance to Gentamicin was significantly high; this is not unexpected because of the use of antibiotics on the bird feeds, particularly through agriculture-influenced and urban-influenced treated and untreated water. Such water samples have all been reported to harbour either bacteria, which carry (multiple) antibiotic-resistance genes, or plasmids carrying these genes [26]. The multidrug-resistance bacteria isolates identified in this study may be due to the 
indiscriminate use of antimicrobial agents in poultry. The use of these antibiotics for infection control may ultimately favor the widespread of drug-resistant strains in the environment [27].

\section{Conclusion}

This study indicates that poultry dung is a carrier of pathogenic bacteria which is capable of transmitting antibiotic resistance genes to human. The most resistant organisms isolated were E. coli and Proteus spp with the latter having the highest frequency. The study calls for close monitoring of antibiotic resistance in our environment and controlled use of antibiotics in poultry since the birds serve as a source of protein and a staple in many homes. The use of the bird droppings for manure is also a call for concern because of the health hazard to the general populace when crops are consumed.

\section{Funding Statement}

This work received no specific grant from any funding agency.

\section{Conflicts of Interest}

The authors declare no conflicts of interest regarding the publication of this paper.

\section{References}

[1] Maron, D.F. (2016) Superbug Explosion Triggers UN General Assemble (UNGA) Meeting. Scientific America.

https://www.scientificamerican.com/article/superbug-explosion-triggers-u-n-gener al-assembly-meeting/

[2] Office International des Epizooties (2015) Fact Sheet on Antimicrobial Resistance. https://rr-africa.oie.int/wp-content/uploads/2019/09/antibio en.pdf

[3] O’Neil, J. (2016) Tackling Drug-Resistant Infections Globally: Final Report and Recommendations. Review on Antimicrobial Resistance. Welcome Trust and UK Government.

https://amr-review.org/sites/default/files/160518 Final\%20paper with\%20cover.pdf

[4] Hao, H.H., Cheng, G.Y., Iqbal, Z., Ai, X.H., Hussain, H.I., Huang, L.L., Dai, M.H., Wang, Y.L., Liu, Z.L. and Yuan, Z.H. (2014) Benefits and Risks of Antimicrobial Use in Food-Producing Animals. Frontiers in Microbiology, 5, 288. https://doi.org/10.3389/fmicb.2014.00288

[5] Caprioli, A., Busani, L., Martel, J.L. and Helmuth, R. (2000) Monitoring of Antibiotic Resistance in Bacteria of Animal Origin: Epidemiological and Microbiological Methodologies. International Journal of Antimicrobial Agents, 14, 295-301. https://doi.org/10.1016/S0924-8579(00)00140-0

[6] Mulani, M.S., Kamble, E.E., Kumkar, S.N., Tawre, M.S. and Pardesi, K.R. (2019) Emerging Strategies to Combat ESKAPE Pathogens in the Era of Antimicrobial Resistance: A Review. Frontiers in Microbiology, 10, 539. https://doi.org/10.3389/fmicb.2019.00539

[7] Teale, C.J. and Moulin, G. (2012) Prudent Use Guidelines: A Review of Existing 
Veterinary Guidelines. Revue Scientifique et Technique (International Office of Epizootics), 31, 343-354.

[8] Catry, B., Cavaleri, M., Baptiste, K., Grave, K., Grein, K., Holm, A., Jukes, H., Liebana, E., Navas, A.L., Mackay, D. and Magiorakos, A.P. (2015) Use of Colistin-Containing Products within the European Union and European Economic Area (EU/EEA): Development of Resistance in Animals and Possible Impact on Human and Animal Health. International Journal of Antimicrobial Agents, 46, 297-306. https://doi.org/10.1016/j.ijantimicag.2015.06.005

[9] Perovic, O. and Schultsz, C. (2016) Stepwise Approach for Implementation of Antimicrobial Resistance Surveillance in Africa. African Journal of Laboratory Medicine, 5, a482. https://doi.org/10.4102/ajlm.v5i3.482

[10] Mthembu, M.S. (2008) The Usefulness of Multiple Antibiotic Resistance (MAR) Indexing Technique in Differentiating Fecal Coliform Bacteria from Different Sources. Doctoral Dissertation, University of Zululand, Empangeni.

[11] Sandhu, R., Dahiya, S. and Sayal, P. (2016) Evaluation of Multiple Antibiotic Resistance (MAR) Index and Doxycycline Susceptibility of Acinetobacter Species among Inpatients. Indian Journal of Microbial Research, 3, 299-304.

[12] Ejiofor, S.O., Edeh, A.D., Ezeudu, C.E., Gugu, T.H. and Oli, A.N. (2016) Multi-Drug Resistant Acute Otitis Media amongst Children Attending Out-Patient Clinic in Chukwuemeka Odumegwu Ojukwu University Teaching Hospital, Awka, South-East Nigeria. Advances in Microbiology, 6, 495-501. https://doi.org/10.4236/aim.2016.67049

[13] Brown, A.E. (2005) Benson's Microbiological Applications: Laboratory Manual in General Microbiology. McGraw-Hill, Inc., New York, 25-35.

[14] Cheesebrough, M. (2009) Medical Laboratory Manual for Tropical Countries. Microbiology, 2, 400-480. https://www.cambridge.org/9780521676304

[15] Clinical and Laboratory Standards Institute (2014) Performance Standards for Antimicrobial Susceptibility Testing; Eighteenth Information Supplement. 28th Edition. https://clsi.org/media/1930/m100ed28 sample.pdf

[16] Chika, E., Ifeanyichukwu, I., Clement, O.A., Malachy, U., Peter, E., Chidinma, I.S., Lilian, O. and Chinedu, O. (2017) Multiple Antibiotic Resistance, Antibiogram and Phenotypic Detection of Metallo-Beta-Lactamase (MBL) from Escherichia coli of Poultry Origin. Journal of Applied Microbiology and Biochemistry, 1, 15. https://doi.org/10.21767/2576-1412.100015

[17] Oyinloye, J.M.A. and Ezekiel, C.N. (2011) Extended Spectrum Beta-Lactamase (ESBL)-Producing Multidrug Resistant Enterobacteriaceae from Commercial Poultry Feeds in Nigeria. Annals of Biological Research, 2, 250-254.

[18] Adegunloye, D.V. (2006) Microorganisms Associated with Poultry Faeces. Journal of Food Agriculture and Environment, 4, 41-42.

[19] Omojowo, F and Omojasola, F. (2013) Antibiotic Resistance Pattern of Bacterial Pathogens Isolated from Poultry Manure Used to Fertilize Fish Pond in New Bussa, Nigeria. Albanian Journal of Agricultural Science, 12, 81-85.

[20] Afunwa, R.A, Odimegwu, D.C, Iroha, R.I. and Esimone, C.O. (2011) Antimicrobial Resistance Status and Prevalence Rates of Extended Spectrum Beta-Lactamase Producers Isolated from a Mixed Population. Bosnian Journal of Basic Medical Science, 11, 91-96. https://doi.org/10.17305/bjbms.2011.2588

[21] Ajayi, A.O. and Egbebi, A.O. (2011) Antibiotic Susceptibility of Salmonella typhi and Klebsiella pneumoniae from Poultry and Local Birds in Ado-Ekiti, Ekiti-State, Nigeria. Annals of Biological Research, 2, 431-437. 
[22] Riaz, S., Faisal, M. and Hasnain, S. (2011) Antibiotic Susceptibility Pattern and Multiple Antibiotic Resistance (MAR) Calculation of Extended Spectrum $\beta$-Lactamase (ESBL) Producing Escherichia coli and Klebsiella Species in Pakistan. African Journal of Biotechnology, 10, 6325-6331.

[23] Osundiya, O.O., Oladele, R.O. and Oduyebo, O. (2013) Multiple Antibiotic Resistance (MAR) Indices of Pseudomonas and Klebsiella Species Isolates in Lagos University Teaching Hospital. African Journal of Clinical and Experimental Microbiology, 14, 164-168. https://doi.org/10.4314/ajcem.v14i3.8

[24] Olayinka, A.T., Onile, B.A. and Olayinka, B.O. (2009) Antibiotic Susceptibility and Plasmid Pattern of Pseudomonas aeruginosa from the Surgical Unit of a University Teaching Hospital in North Central Nigeria. International Journal of Medicine and Medical Sciences, 1, 79-83.

[25] Hemen, J.T., Johnson, J.T., Ambo, E.E., Ekam, V.S., Odey, M.O. and Filia, W.A. (2012) Multi Antibiotic Resistance of Some Gram Negative Bacterial Isolates from Poultry Litters of Selected Farms in Benue State. International Journal of Science and Technology, 2, 543-547.

[26] Schwartz, T., Hoffmann, S. and Obst, U. (2013) Formation of Natural Biofilms during Chlorine Dioxide and U.V. Disinfection in a Public Drinking Water Distribution System. Journal of Applied Microbiology, 95, 591-601. https://doi.org/10.1046/j.1365-2672.2003.02019.x

[27] Muhammad, A.A., Saidul, A., Hassan, S.M. and Momena, S. (2009) Antibiotic Resistance of E. coli Isolated from Poultry and Poultry Environment of Bangladesh. Internet Journal of Food Safety, 11, 19-23. https://doi.org/10.3844/ajes.2009.47.52 